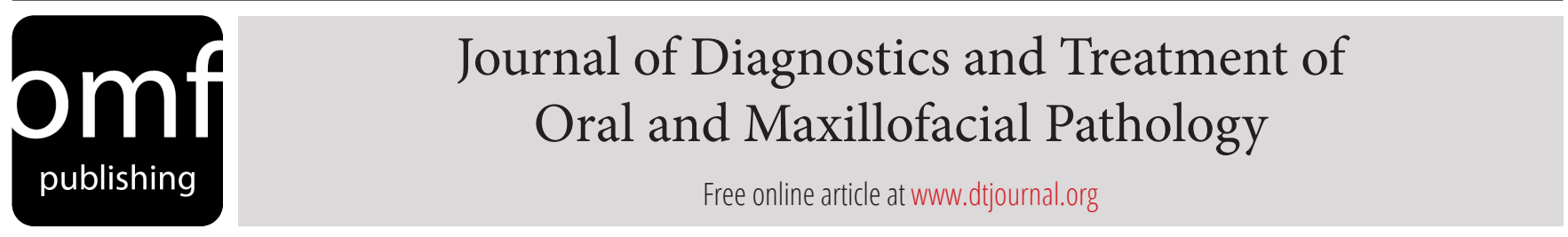

\title{
Two Great Founders
}

Editorial

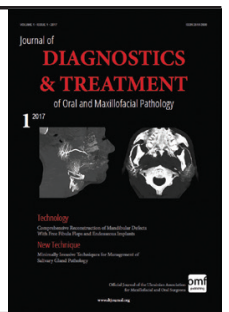

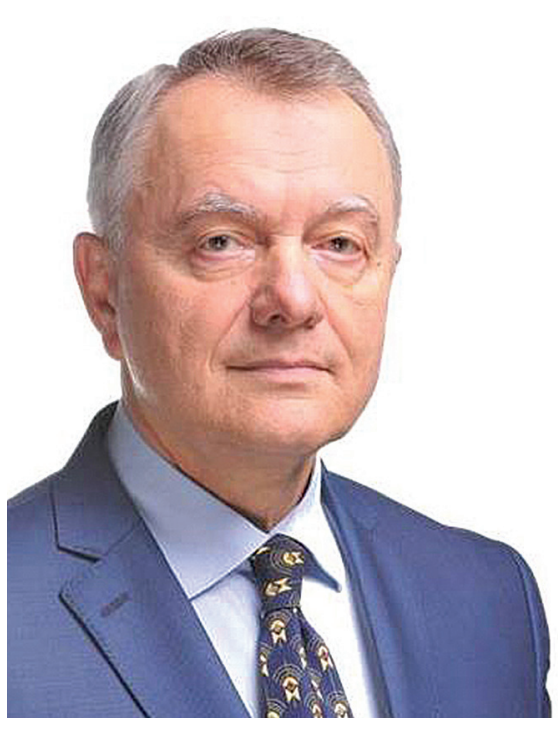

In December 2016 the co-founder of the Journal Yuriy V. Voronenko was re-elected to rector position at the Shupyk National Medical Academy of Postgraduate Education! The Academy became a leading Educational Institution in the Eastern Europe under his leadership. Prof Voronenko is an author of over 400 scientific works, and also author and co-author of 11 textbooks, 25 educational and methodical manuals, 38 monographs. He mentored $12 \mathrm{ScD}$ and $11 \mathrm{PhD}$.

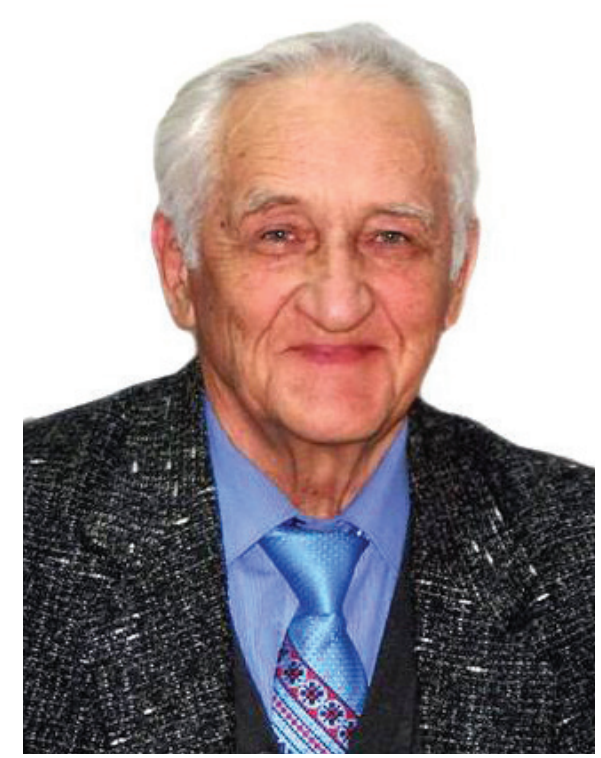

Yuriy V. Voronenko MD, ScD, Professor, is an academician of the National Academy of Medical Sciences of Ukraine, Ukraine State Prize Winner in Science and Technology, Honored Science and Technology Worker of Ukraine. Under the rector's Voronenko support the 40 scientific journals are developed (the Journal of Innovative Technology Medicine, the Journal of Cardiac Surgery and Interventional Cardiology etc.).

So, the Editorial of the Journal is congratulate Prof Voronenko with a re-election and wishes him to create such great opportunities for our medical colleagues as for founding our Journal!
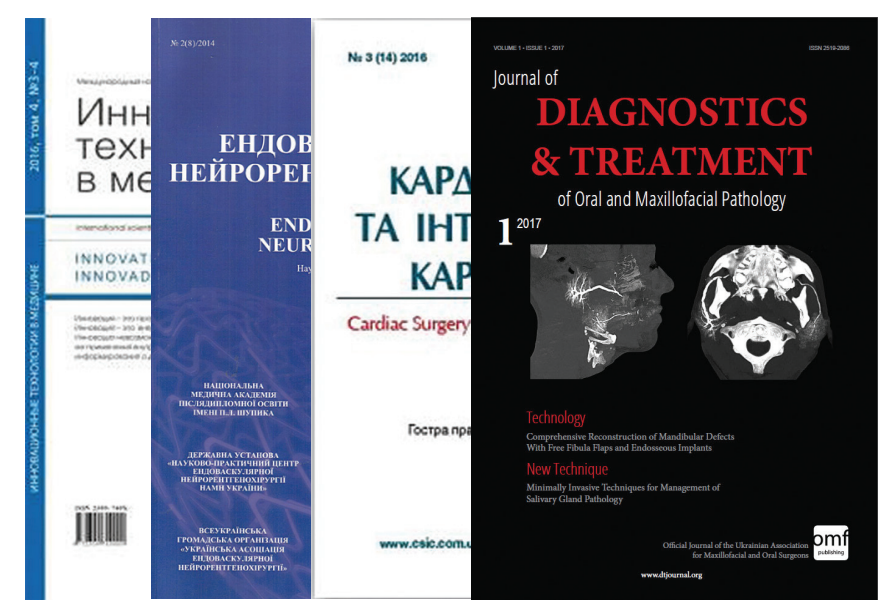

In December 16, 2016 the other Great Founder, the Founder of the Kyiv Medical University of UAFM Victor A. Tumanov was celebrated 80 years!

Prof Tumanov was a rector of Kyiv Medical University UAFM from 1994 to 2006 and now is honorary rector of this guiding institution.

Prof Tumanov is awarded by numerous state awards and is an editorial board member of many scientific journals.

With deep respect for the titanic work and achievements of the Professor we wish him for the anniversary a strong health to lead the University to the new heights! 